\section{Insights About Nuclear Medicine Technology: Findings from a 2006 Survey of NMT Education Program Directors}

TO THE EDITOR: I must register my protest against the article "Insights about Nuclear Medicine Technology: Findings from a 2006 Survey of NMT Education Program Directors" by the Center for Health Workforce Studies at the State University of New York at Rensselaer (1). I believe this article should have been published as 2 separate articles: the data from the survey and the recommendations. It is the latter with which I take issue.

The recommendations produced by the (unidentified) authors of this paper do not in my opinion follow from the survey results. The first paragraph of the recommendations states that they arise from "the open-ended comments presented in Appendix B, supplemented by conversations with practitioners and leaders in the NMT profession." There is no Appendix B included in the print version of the paper, nor is it available as advertised on the SNM Web site. I believe that only the very last part of the authors' statement is true, and the recommendations are those of the SNM Technologist Section (SNMTS) leadership. I believe they have been disguised as resulting from survey data when in reality the survey itself did not directly address many of the recommendations that the article makes.

I will provide 2 examples of the disconnect between survey and recommendations. The first falls under the first recommendation bullet, which states that the correct entry-level credential for nuclear medicine technologists should be a bachelor's degree. This is a position that has been promoted by SNMTS leadership for several years. However, the responses to the survey question are easy to predict. Bachelor-degree program directors are of course in favor of requiring a bachelor's degree as the entry-level credential. But the question by its very nature will be answered negatively by associate-degree program directors, whose livelihoods are directly challenged by its asking. The recommendation does not capture the diversity of opinion among program directors but simply voices the SNMTS leadership position.

The second example relates to education in sectional anatomy. The survey question asked if a program currently offers instruction in sectional anatomy, not whether we thought it should be included. In actuality, many program directors are actively working to add sectional anatomy to their programs but are deemed "complacent" because they have not already done so.

As a program director who completed the survey, I am concerned that the recommendations will be interpreted as the "voice" of the program directors, when the recommendations really address concerns and biases of the SNMTS leadership. I feel that the recommendations make program directors appear uninterested in advances within their profession, when in fact the survey instrument asked only what the directors are currently doing. And I am most distressed that the JNMT would publish what I consider to be an opinion piece under the guise of survey results.

\section{REFERENCE}

1. Insights about nuclear medicine technology: findings from a 2006 survey of NMT education program directors. J Nucl Med Technol. 2007;35:42-49.

\author{
Jennifer L. Prekeges, CNMT \\ Bellevue Community College \\ Bellevue, Washington
}

DOI: $10.2967 /$ jnmt.107.042689

REPLY: Let me begin with a clarification. My colleague, Margaret Langelier, and I at the Center for Health Workforce Studies at the University at Albany were the authors of the article in question. Ms. Prekeges is correct that many of our recommendations coincide with positions taken by the SNMTS leadership in recent years. This is true not because we were trying to endear ourselves to SNMTS leaders but because, based on our judgment about what would be best for the nuclear medicine technologist (NMT) profession, we believe that our recommendations are appropriate ways to build the status and reputation of the NMT profession, and ultimately, to better serve people needing nuclear medicine procedures.

A second clarification is that the full report on which the article is based is posted on the SNM Web site, though not perhaps in the most logical location. The URL is http://interactive.snm.org/docs/ NMT_Educator_Report_2006.pdf.

Margie and I made a serious attempt in this report to "capture the diversity of opinion among program directors." We recognize that, as is true in many health professions, recommendations to upgrade the basic academic credential to the BS degree will be viewed unfavorably by directors of associate degree programs. On the other hand, we also recognize that other "superior" professions often find it difficult to include professionals with "only" associate degree credentials in serious policy discussions, even though the individuals might bring as much or more insight and intellect to the discussion as those in their own profession.

In her second example, Ms. Prekeges is correct that our survey asked about current practices, and our recommendations are opinions about what we think would be appropriate for the NMT profession. We did make an effort to distinguish the two by including our recommendations in a separate section in the article, but perhaps we should have been more explicit about what was based on survey responses and what was our expert opinion. In any case, we hope that readers take to heart our recommendations, which are based on a variety of sources and experiences. We believe that failure to follow through with some of them could jeopardize the future of the NMT profession.

Paul Wing
Center for Health Workforce Studies
Rensselaer, New York

DOI: $10.2967 / j n m t .107 .047183$ 